\title{
Managing by Sustainable Innovational Values (MSIV): An Asymmetrical Culture Reengineering Model of Values Embedding User Innovators and User Entrepreneurs
}

\author{
João Brillo ${ }^{1}$, Kristine Marin Kawamura ${ }^{2}$, Simon L. Dolan ${ }^{3} \&$ Xavier Fernández-i-Marín ${ }^{4}$ \\ ${ }^{1}$ Visiting Professor, ESADE Future of Work Unit, ESADE Business School, Ramon Llull University / CAPES \\ Foundation, Ministry of Education of Brazil \\ ${ }^{2}$ Professor of Management, St. Georges University \\ ${ }^{3}$ Professor, ESADE Future of Work Chair, ESADE Business Scholl, Ramon Llull University \\ ${ }^{4}$ Senior Researcher, ESADE Future of Work Unit, ESADE Business School, Ramon Llull University \\ Correspondence: João Brillo, Visiting Professor, ESADE Future of Work Unit, ESADE Business School, \\ Ramon Llull University / CAPES Foundation, Ministry of Education of Brazil. E-mail: \\ joaobatista.brillo@esade.edu
}

Received: April 14, 2015 Accepted: June 10, 2015 Online Published: August 28, 2015

doi:10.5539/jms.v5n3p61 URL: http://dx.doi.org/10.5539/jms.v5n3p61

The authors are grateful to the financial assistance of EU-InnovatE project (http://eu-innovate.org/en), which helped develop this work. Grant No. 613194.

\begin{abstract}
Today's critical success factor for public and private enterprises is their capability to develop, adapt, promote, and successfully manage sustainable innovation processes. Firms that are able to successfully manage sustainable innovation processes can competitively operate in mature markets while refocusing their strategies to open up new markets and target new customer segments. With knowledge becoming the main resource of global firms, the capacity to develop sustainable innovation strategies, cultures, and processes enables firms to capitalize on their strategic human resources and management systems. Sustainable innovation mandates that firms leverage both tacit and explicit resources and the talent of user-innovators and user-entrepreneurs, developing sustainable innovation routines and results. In addition to these traditional requirements, we argue that the firm's ability to identify, embed, and manage organizational, managerial, and personal values within their cultures provides the core foundation for inspiring, motivating, and energizing creativity and innovation across the firm. Leaders, managers, employees, and users who share these core values, can achieve sustainable innovation. This perspective supports the growing recognition by academics and practitioners for managers to utilize socially-responsible management practices and activities to simultaneously fuel innovation and create a better, more sustainable and more harmonious world.

The aim of this paper is to present and further elaborate a prototype of the "Management by Sustainable Innovational Values" (MSIV) model that was recently published (Brillo, Dolan, \& Kawamura, 2014). The MSIV model proposes that sustainable innovation best occurs when certain values are identified, shared, and operationalized across the organization, and, more specifically, when organizational members are passionate about their work because they share emotional values to an even greater degree than economic or social ones. While the MSIV model does not ignore economic and social values as drivers of performance and firm survival, it is argued that sustainable innovation may best occur when emotional values work in conjunction with economic values, and when these values are embedded within the firm's culture.
\end{abstract}

Keywords: open/sustainable Innovation, user-innovators /user-entrepreneurs, economical-emotional-social/ecological values, innovational/entrepreneurial coach 


\section{Introduction}

We live in a changing and transforming world, one in which firms and societies face a wide-range of human, resource, organizational, social, and environmental crises, yet they lack the ability to develop the innovation environments that enable high-quality sustainable solutions and the innovation engines that allow them to constantly innovate and renovate. According to Francis and Bessant (2005), innovation can be achieved in four spaces: P1 -innovation in product introduction or improvement $\mathbf{P 2}$-innovation in process introduction or improvement; P3 - innovation in the definition or redefinition of the positioning of products/services, and $\mathbf{P 4}$ - innovation in the definition or redefinition of the dominant paradigm - the mindset or the shared values - of the firm within its ecosystem and towards its stakeholders. Within the firm's P4 innovation space are its ingredients for achieving sustainable innovation: the firm's values-driven resources (including ecological values), managerial capacity, innovation management capabilities, culture and strategy, and embedded core businesses processes that drive sustainable innovation.

In the last several years, academics and practitioners have seen the emergence of user-centered innovation strategies and practices in addition to those associated with traditional firm-based innovation. User-centered innovation processes offer advantages over firm-centric innovation development systems: the individual is no longer simply regarded as a buyer with needs for manufacturers to identify and serve, but as individuals that develop their own solutions, therefore becoming users and innovators (or what we call "user-innovators"). This process is being driven by two trends: one associated with firm capabilities and the other associated with firm coordination. First, computer hardware and software democratizes access to tools that were only possible in a firm environment before. This makes citizens more capable of engaging in their own solutions (innovations) for their problems. Secondly, Internet has greatly improved the ability of users to coordinate their efforts, so that more complex endeavors can now be produced as a result of coordinated individuals (Von Hippel, 2005).

Management by Sustainable Innovational Values - hereafter MSIV - is presented in this paper as a leadership tool to deal with open innovation environments, helping leaders, managers, and their organizations face the many management challenges of the 21st century. Given the number of simultaneous transformations and challenges occurring around the world, i.e., the growing global population, an increasing level of migration and mega cities, a constant search for new ways of creating a decent life, the energy crisis, infrastructure collapses, the growing global divide, comprehensive access to education, and the "metaverse" and singularity ofvirtual reality (Raich \& Dolan, 2008; Raich, Eisler, \& Dolan, 2014), we argue that managers and leaders - and all organizational members, in fact - need to abandon old paradigms and develop new ones for the sake of our survival and the survival of future generations (Raich, Eisler, \& Dolan, 2014). In this paper, we derive MSIV as a platform for use in motivating people and organizations to more precisely identify future scenarios while also developing competencies to address effectively just-in-time challenging events.

\section{Integrating User-Innovators and User-Entrepreneurs for Sustainable Innovation Results}

The qualities and characteristic of innovation normally are complex, uncertain, and almost, but not quite, impossible to manage. Because there is no perfect, or one-size-fits-all, approach for firms to conduct innovation management, there will always be opportunities for experimentation and continuous improvement. Innovation is also needed to fully develop long-term sustainability for people, organizations, and societies; yet here, too, there is no single method for this to occur. The notion of sustainability, itself, may benefit by continuous innovation by embedding values throughout all its processes, moving us towards the notion of values-based sustainability innovation.

In the past, success in innovation has depended upon two key ingredients: technical resources (people, equipment, knowledge, money, and values); and the capabilities in the organization to manage them. Both ingredients have values-based components. The scope for innovation is wide: innovation occurs within an innovation space (traditionally defined by paradigm, product, position and process) within which an organization can operate and innovate (Frances \& Bessant, 2005), with both incremental and more radical options, opportunities for discontinuous change, and aspects of component and architectural innovation (Tidd \& Bessant, 2013). Because a firm's innovation space may now be created beyond the traditionally-defined boundaries of the firm through open innovation strategies, the study of innovation is ripe for an adopted model that incorporates an even wider scope, one that includes human and social perspectives and new sources for innovation projects and market place differentiation outside traditional innovation definitions.

According to Tidd \& Bessant (2013), innovation is a core business process that needs to be organized and managed in order to enable the renewal of any organization. The innovation process model includes the steps of search, strategic selection, and implementation, and value capture. For successful innovation management to occur, 
innovative organizations require several components: shared vision, leadership, and the will to innovate; an appropriate structure; key individuals; effectively working teams; a high-involvement innovation culture; a creative climate; and an internal and external customer orientation (Tidd \& Bessant, 2013). Sustainable innovation valuesalso need to be embedded within all these components in order for innovation to be deeply rooted in the firm's business model. For innovation to be part of the human and knowledge resources of the firm, innovation needs to be enlivened through sustainable innovation values that provide the fuel for innovation at the level of the firm's ecosystem and stakeholders, strategy, culture, management system, and individual members. This will enable innovation to be fueled through the passion that values bring to the firm's leaders, managers, members, and stakeholders.

Research shows that there is a road map for building an innovative organization, progressing in terms of the development of systems and capability to involve people and in terms of bottom line benefits for creating a "high-involvement" innovatory organization or reaching "high-involvement" innovation. While many believe that training and development is the driver to innovation (ASTD, 2014) (Note 1), others, such as Tidd \& Bessant (2013), argue that firms move through five innovation stages: 1) natural, 2) structured, 3) goal-oriented, 4) proactive/empowered and 5) full capability. Full capability is achieved when the firm becomes a values-based learning organization. Furthermore, firms can generate innovation energy-the DNA that spawns innovation - when three forces converge: the Individual's attitude; a group's behavioral dynamic; and the support an organization provides (Tidd \& Bessant, 2013). Innovation energy is also created through an innovation climate that is based on trust and openness. In such climates, also characterized by high challenge and involvement, respectful conflict and open debate, sustainable innovation can best be developed. Furthermore, firms that embrace the user as part of their innovation process and additional source of innovation energy - utilizing user-centered innovation rather than traditional firm-based innovation, in other words-gains advances because the users are developing their own solutions, becoming user innovators, associating their capabilities with democratize access coordination (Von Hippel, 2005).

A central thesis of an on-going the European project "Sustainable Lifestyles 2.0: End User Integration and Entrepreneurship" (EU-InnovatE) (Note 2) is that user-innovators and user-entrepreneurs are playing an essential role, over time, as drivers of innovation as firms and societies recognize the need to transition to sustainable energy, food, living, and mobility. The two major concepts of this scientific investigation project are: 1) the recognition of the role that endusers and user-entrepreneurs play in driving sustainable innovational processes; and 2) the long term opportunities and obstacles for company-driven and user-driven sustainability innovations in the Multi-Level Perspective (MPL). According to EU-InnovatE General Assembly (2015) discussions, there are different rules associated with user-innovators and user-entrepreneurs in the transition towards a more sustainable innovation future with respect to their core competencies and elected models of leadership. Entrepreneurship plays an important transformational role in the development of a more sustainable future, balancing the triple bottom line of economic, social and ecological goals (Belz \& Binder, 2015). Figure 1 shows a sketch of the mentioned discussions.

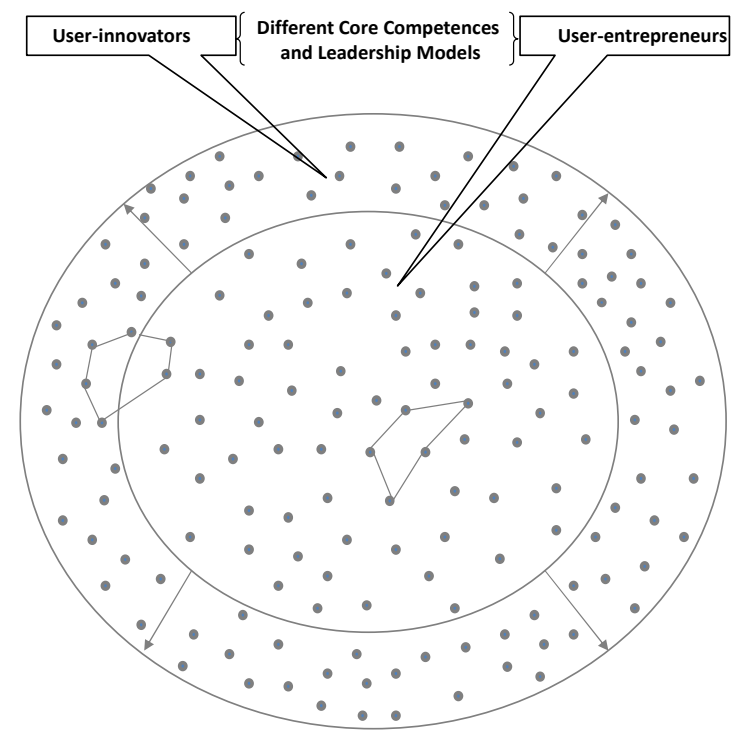

Figure 1. User-innovators and user-entrepreneurs: two different profiles 
Wesuggest that MSIV model can be a useful tool to integrate the notions of user-innovators, user-entrepreneurs, and sustainable innovation along with concepts of values-driven organizational resources and values-based managerial capabilities (including economical-emotional-social/ecologicalvalues). It is suggested that user-innovators are driven more by emotional values (than the other categories) while user-entrepreneurs are driven more by economical values - both of which simultaneously affect how innovation as a core business process is embedded in the organization's leadership, strategy, goals and culture, according to these different profiles.

\section{Sustainable Innovation Demands a New Leadership Model}

MSIV is presented hereafter as a leadership tool to deal with open sustainable innovation environments, helping leaders, managers, and their organizations face the many management challenges of the 21 st century-a time in which leaders and their organizations recognize the crucial role that sustainable innovation plays in their strategies and survivability. Many firms, today, are utilizing open innovation approaches in their innovation strategies. According to Chesbrough (2003), open innovation approaches are effective when organizations "open up" their innovation process outside the traditional boundaries of the firm by involving external actors such as scientists, suppliers, and customers into their product and service development processes while also adapting common tools for the integration of end users in the generation of creative sustainability ideas, concepts, and prototypes. The main advantages of this practice are: new creative ideas, thinking "out of the box"; tailoring products to latent needs and wants; and reducing the risks of market failures. The practice of open innovation in the Spanish market has shown to be highly-effective under two conditions: there is a true collaborative effort with customers within the innovation process; and the business innovation system adapts to the characteristics of the market demands, taking into account technological and social changes. The model offered shows that the generation of organizational improvement in the initiatives of customers' co-creation in innovative processes is the key ingredient to success (Pablo-Heredero et al., 2012). Open innovation, however, is hard to achieve and hard to manage. In fact, of the many reasons that these strategies fail, one of the major ones is that leaders and managers talk about innovation, but they do not walk the genuine innovational path.

MSIV is proposed as an asymmetrical culture reengineering model of values; it acts as a management system that allows managers of innovative firms to integrate user-innovators, user-entrepreneurs, sustainable innovation practices (such as values-driven organizational resources and values-driven managerial capabilities-including economical-emotional-social/ecological values) - and the core business processesthat are embedded in the organization, strategy, goals, and culture. The MSIV model of values is an extension and elaboration of the "Coaching by Sustainable Innovational Values" (Brillo, Dolan, \& Kawamura, 2014), the "Managing by Values" (Dolan, Garcia, \& Richley, 2006) and the "Coaching by Values" concepts (Dolan, 2011). There are several books and articles published calling to incorporate several levels of analysis in order to overcome the fragmented view of sustainability. More and more scholars, for example, are calling to embed people, planet, and profits as integral components of the firm's strategy and strategic goals and as part of a holistic model of sustainability (Cavagnro \& Curiel, 2012; Wirtenberg, 2014). In order to help leaders and managers create a sustainable innovative environment, we wish to contribute to the debate some scenarios within the framework of the three-level definition of MSIV that incorporates People, Organization, and The World. Figure 2 provides a schematic presentation of the mentioned model. 


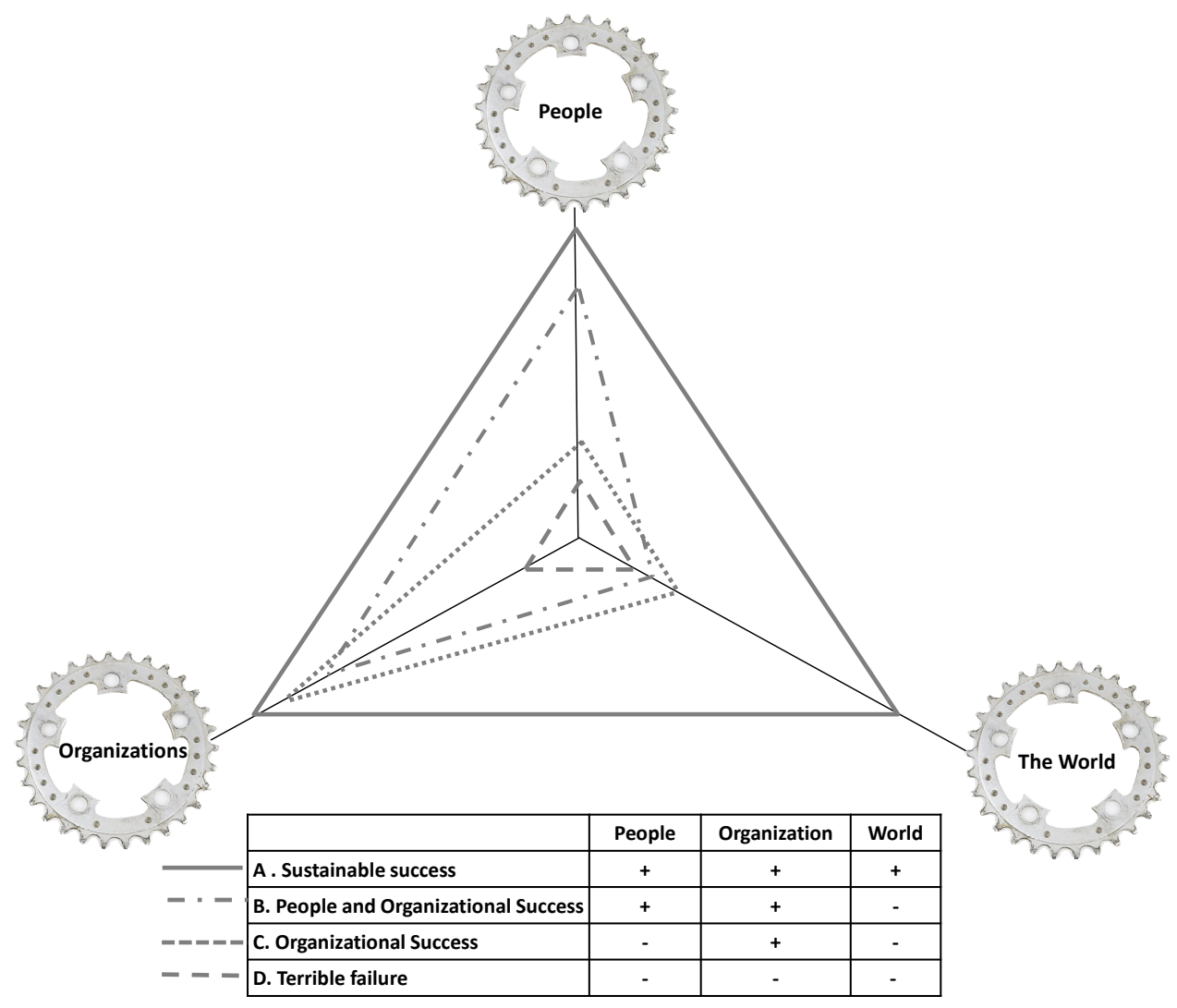

Figure 2. MSIV model and the principal predictable scenarios

Modified from: Brillo, J., Dolan, S., and Kawamura, K., Coaching by Sustainable Innovational Values (CSIV): Portraying the case of the 40-30-30 tri-intersectional model, SSRN, 12/2014.

Scenario D represents a lose-lose-lose situation - a realistic possibility because the new world is so global and complex that its resulting chaos could even lead to the destruction of our civilization (Dolan \& Raich, 2008). Scenario $\mathbf{C}$ occurs when only organizations win, mainly due to absence of empathy that originates from the capacity to treat people the same way you want them to treat you (Matthew 7:12). Scenario B is a problematic zone, where organizations and people win but the world loses. "The win is not complete because both win but they do not care about Heaven and Earth" (Sun Tzu, circa 500 BC). Scenario A represents a true win-win-win situation. This position is a fertile environment for realizing the benefits of the sustainable innovation management approach.

\section{The Evolution of Management Models}

The big wave of changes during the 21 st century, with its increasing speed and transformation forces, challenges organizations and societies to develop sustainable innovation solutions. In such a complex context of uncertainties, dualities, and paradoxes, the task cannot be easily prescribed. According to Dolan and Garcia (2002) and Dolan, Garcia and Richely (2006), we have journeyed through several eras in management systems; the early $20^{\text {th }}$ century was characterized by systems of mass production and automation, whereby the underlying paradigm was efficiency; the corresponding management philosophy was coined "Management by Instruction" (MBI). With MBI, few people made the key decisions, and the remainder of the people in the organizations, even their customers, just followed the instructions. In the middle of the $20^{\text {th }}$ century, the level of environmental complexity became higher, and MBI did not work. Thus, a new management system emerged that was coined "Management by Objectives" (MBO). MBO combined the activities of several stakeholders to ensure that results were accomplished, mixing both efficiency and effectiveness paradigms while also respecting legal framework and market conditions but providing less concern to broader sustainable concerns. Management by Values (MBV) emerged at the beginning of the $21^{\text {st }}$ century, a time in which all stakeholders activities and needs changed, environmental crises abounded (e.g., climate, water, air, population explosion and terrorism), and the 
volatility created more awareness across all stakeholders - further exacerbated by higher levels of education of the workforce, the phenomenon of information explosion, instant communication via mobile communication devices, and the fear of nuclear disasters. MBV represents a new form of management system, created for individuals who can see and sense the world in a more holistic manner, and tailored to people that are more sensitive to the combined effects of the ecology, the social fabric of society, the economic system including the harnessing of new technologies, and the search for self-actualization and passion for their actions (Dolan, 2011; Raich, Eisler, \& Dolan, 2014). As everything is in evolution, Management by Sustainable Innovational Values (MSIV) is a recently-developed framework that may be used to deal with open sustainable innovation environments - for which the act of balancing traditional management skills with innovating ones is critically neededin order to develop a sustainable highly-performing organizational culture. Figure 3 shows the evolution of these management models.

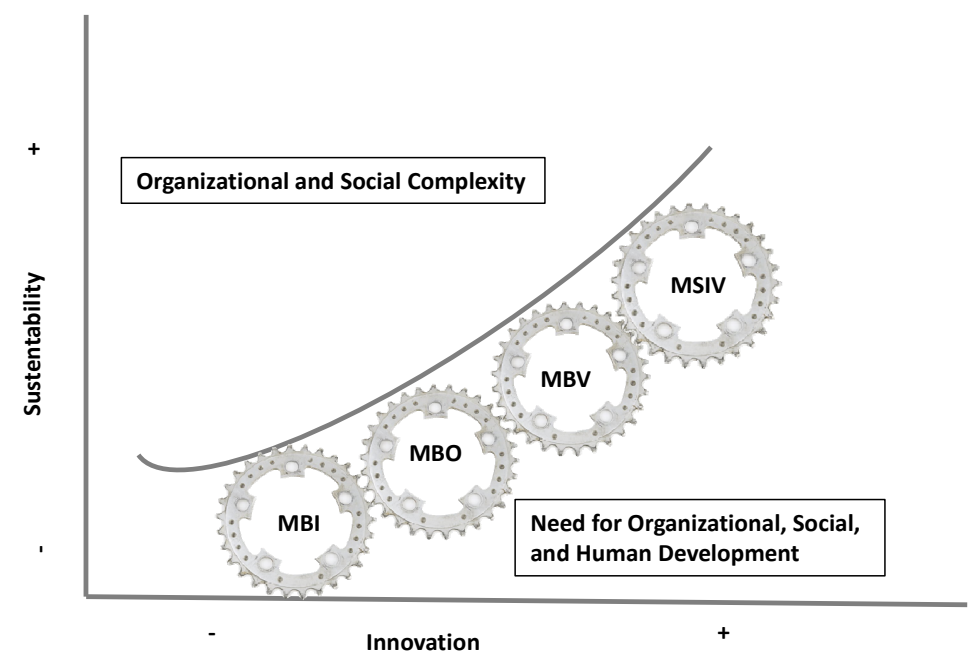

Figure 3. Management models evolution

The four management models represented by MBI, MBO, MBV, and MSIV may be distinguished one from the other on the basis of their primary characteristics, summarized in Figure 4.

\begin{tabular}{|l|l|l|l|l|}
\hline & MBI & MBO & MBV & MSIV \\
\hline $\begin{array}{l}\text { Preferable } \\
\text { situation for } \\
\text { application }\end{array}$ & $\begin{array}{l}\text { Routine work or } \\
\text { emergencies }\end{array}$ & $\begin{array}{l}\text { Moderately } \\
\text { complex } \\
\text { Relatively } \\
\text { standardized } \\
\text { production }\end{array}$ & $\begin{array}{l}\text { Need for } \\
\text { creativity to solve } \\
\text { complex } \\
\text { problems }\end{array}$ & $\begin{array}{l}\text { Innovatory } \\
\text { organization: } \\
\text { strategy, culture, } \\
\text { management, } \\
\text { process }\end{array}$ \\
\hline $\begin{array}{l}\text { Type of } \\
\text { leadership }\end{array}$ & $\begin{array}{l}\text { Traditional, } \\
\text { hierarchical }\end{array}$ & $\begin{array}{l}\text { Focused on } \\
\text { resources allocation }\end{array}$ & Transformational & $\begin{array}{l}\text { Inner driven, } \\
\text { outer connected }\end{array}$ \\
\hline $\begin{array}{l}\text { Image of } \\
\text { customer }\end{array}$ & User buyer & User customer & $\begin{array}{l}\text { Discriminating } \\
\text { customer with } \\
\text { freedom of } \\
\text { choice }\end{array}$ & $\begin{array}{l}\text { Global and web- } \\
\text { based customers }\end{array}$ \\
\hline $\begin{array}{l}\text { Product market } \\
\text { type }\end{array}$ & $\begin{array}{l}\text { Monopolistic, } \\
\text { standardized }\end{array}$ & Segmented & $\begin{array}{l}\text { Highly } \\
\text { diversified, } \\
\text { dynamic }\end{array}$ & $\begin{array}{l}\text { Open innovation, } \\
\text { co-creation }\end{array}$ \\
\hline $\begin{array}{l}\text { Social } \\
\text { organization } \\
\text { relationships }\end{array}$ & $\begin{array}{l}\text { Top-down } \\
\text { control, } \\
\text { supervision }\end{array}$ & $\begin{array}{l}\text { Control and } \\
\text { stimulation of } \\
\text { professional } \\
\text { performance }\end{array}$ & $\begin{array}{l}\text { Self-supervision } \\
\text { encouraged }\end{array}$ & $\begin{array}{l}\text { Organization to } \\
\text { Society to Human } \\
\text { all connected }\end{array}$ \\
\hline $\begin{array}{l}\text { Purpose of } \\
\text { organization }\end{array}$ & $\begin{array}{l}\text { Maintain } \\
\text { production }\end{array}$ & Optimize results & $\begin{array}{l}\text { Continually } \\
\text { improve process }\end{array}$ & $\begin{array}{l}\text { Sustainable } \\
\text { innovation } \\
\text { results }\end{array}$ \\
\hline $\begin{array}{l}\text { Type of culture } \\
\text { discipline }\end{array}$ & $\begin{array}{l}\text { Loyalty, } \\
\text { conformity, } \\
\text { efficiency }\end{array}$ & $\begin{array}{l}\text { Rationalization, } \\
\text { motivation, } \\
\text { commitment }\end{array}$ & renovation \\
\hline
\end{tabular}

Figure 4. Main primary characteristics of MBI, MBO, MBV, and MSIV

Modified from: Dolan, S., Garcia, S., and Richley, B. (2006), Managing by Values, London. Palgrave Macmillan 
Nowadays, organizations and society are still failing in their ability to deal with natural disasters, technology, human emotions (especially anger, rage, and fear), and the conflict of dreams and despair-all of which require the development of our human capacity for empathy, caring, and creativity (Dolan, Eisler, \& Raich, 2014). More and more research as well as consulting experience suggests that the underlying "meta" value of successful organizations is TRUST: trust between employees, trust in management, trust in customers, trust in partners, and alike (see Tzafrir \& Dolan, 2004; Tzafrir et al., 2004; Tzafrir, 2006; Tzafrir \& Gur, 2007). Thus, MSIV argues that trust should be the core value in the system; without trust, other shared values cannot be built. In his essay "Coaching by Values," Dolan (2011) argued that in eras and firms characterized by advanced management practices, trust should be, by far, more important than the value of control. Quoting a German industrialist by the name of Diener, Dolan suggested that the old management systems (MBI and MBV) were driven by the paradigm of "Trust is good, but control is better" while the new management philosophies of MBV and MSIV require the use of the paradigm "Control is good, but trust is much better." We are also still struggling with the conflict of a domination and partnership culture while progressing from a physical reality to virtual-based reality at an accelerated rate. The previous set of management practices that were part of the MBI and MBO will no longer work. Managers will fail if they insist on using command-and-control-type systems! A typical example of this environment is one in which the modern turnstile is used to control people, which guarantees the physical presence of employees but does not do anything to integrate their minds and their souls.

In the MSIV philosophy, the successful leaders for today's environment as well as in "Tomorrowland" are those that can obtain the commitment of their followers by sharing their values - ensuring that they are aligned with the strategic objectives of the organization - and inspiring their followers to contribute their own values-based power, creativity, and commitment. The sharing of sustainable innovational values guarantees that the minds and souls of employees are committed as much as - if not more than - their physical presences. Moreover, sustainable innovation values represent something constant while everything else might be changing.

\section{MSIV in Cultures Seeking Sustainable Innovation}

The MSIV model is an extension of the MBV tri-axial model, which was proposed as a management system that could be used as the foundation for developing organization culture (Dolan, Garcia, \& Richley, 2006). MSV suggested that central values, goals, and strategic objectives be circumscribed within the triangle that is formed by three complementary yet orthogonal axes: economic-pragmatic, ethical-social, and emotional-developmental. Economic-pragmatic values are a set of values related to the criteria of efficiency, industrious, performance standards, and discipline. These values guide the planning, quality assurance, and accounting activities in organizations: they are necessary in order to maintain and unify various organizational subsystems. Ethical-social values represent the ways in which people behave in groups, guided by ethical values shared by members of a particular group. These values come from conventions or beliefs about how people should behave in public, at work and in their relationships; they are associated with values such as honesty, consistency, respect and loyalty, among others. These values are manifested by actions more than words. Emotional-developmental values are essential in creating new opportunities for action. These values are related to intrinsic motivation, which moves people to believe in a cause. Optimism, passion, energy, freedom and happiness are some examples of these values; without them, people would be unable to make firm commitments or be creative. Therefore, when designing an organizational culture, it is essential that people are able to do what they do best in their jobs.

The MSIV tri-intersectional model suggests an asymmetrical culture reengineering process to occur for firms seeking to develop sustainable innovation. The MSIV culture reengineering process describes a process for alignment and realignment of the three axes (economic-pragmatic, ethical-social, and emotional-developmental) at their points of intersection, focusing on the innovation linkage (with a $40 \%$ weighting rather than $33 \%$ ) - the intersection between the emotional-development axis and the economic-pragmatic axis - that allows managers and leaders to focus on developing sustainable innovation processes in their organizations, while also keeping the sensitivity and survival linkages in an adequate level of 30\%. Exhibit 5 shows the MBV tri-axial model and the MSIV tri-intersectional model with the points of intersection between the 3Es: the intersection of the emotional-development axis and the economic-pragmatic axis leads to greater innovation; the economic-pragmatic axis and the social ethical intersection enhances survival (after all, when a big ethical or social scandal arises, the survival of the firm is at stake); and the intersection of the ethical-development axis with the emotional-developmental axis increase sensitivity and makes the organization more humane and more socially-responsible. 


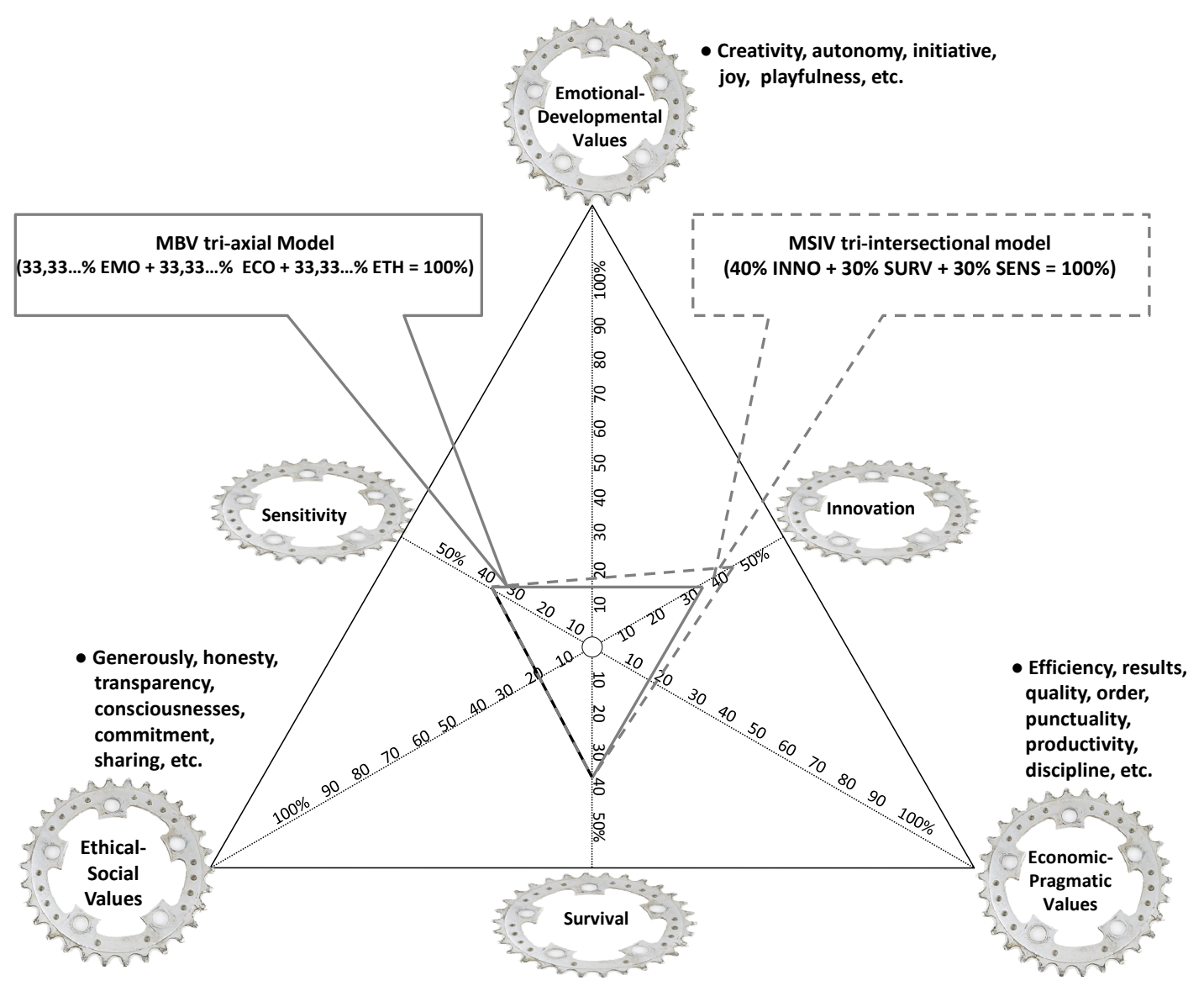

Figure 5. MBV tri-axial model x MSIV tri-intersectional model

Modified from Dolan (2011) op. cit.

An enterprise that simultaneously experiences emotional-developmental/economic-pragmatic values has the management skills to nurture creative ideas and turn them into a commercial reality. One such company that has been able to do this is Royal Dutch Shell. Royal Dutch Shell founded its GameChanger programme in 1996 and has long practiced open innovation, inviting ideas from outside and working with others. The programme has been designed to prove the technical and commercial viability of an idea quickly and affordably. To date, GameChanger has worked with over 1,700 innovators and turned more than 100 ideas into reality, some with massive potential, as the revolutionary idea of cooling natural gas to liquid at sea, or the ingenious idea to house equipment in a giant glasshouse in the process of extracting oil by harnessing the power of the sun more efficiently.

The GameChanger team utilizes several criteria to assess innovative ideas:

- Novel - Is the idea fundamentally different and unproven?

- Valuable - Could the idea create substantial new value if it works?

- Doable - Is there a plan to prove the concept quickly and affordably?

- Relevant - Is the idea relevant to the future of energy?

After answering positively to this question, the next stage is to go to the marketplace. If proof-of-concept is reached successfully, they may also be able to help take the invention to the next stage in which there are three potential forward paths:

- Proprietary-The idea is graduated into Shell's internal R\&D funnel or another Shell business for direct use by Shell.

- Licensing-The idea is licensed to an existing technology provider other than Shell. This is usually applied when complementary capabilities are required to further develop and deploy the idea. 
- Venturing-A new company might be set up to bring the idea to commercial market.

We argue that the GameChanger programme allows for an integration of user-innovators and user-entrepreneurs. It is also in line with the MSIV intersection model of values, describing a process for the alignment and asymmetric realignment of the three axes (economic-pragmatic, emotional-developmental, and ethical-social) at their points of intersection, focusing on the innovation linkage (40\%) - the intersection between the emotional-development axis and the economic-pragmatic axis-that leads their members develop to great innovations, while keeping the sensitivity and survival linkages at adequate levels of $30 \%$.

\section{The Core Competencies Focus on Innovational Values and Organization Culture}

Some organizational strategies emphasize the importance of core innovational competencies (Breen \& Hamel, 2007) as a guarantee for sustaining firm success. Results on the application of the tri-axial values model shows that the demand for competencies that are symmetric to the values have strong predominance of economic-pragmatic competences ( $75 \%$ compared to an average of $59 \%$ ) while ethical-social competencies stay on average (Brillo \& Cosenza, 2013). Results also show that special attention is required for emotional-developmental competences $(42 \%)$, which are rated at a lower level because they enhance the innovation, learning, and critical factors associated with achieving sustainable success for the firm. In the 3Es application, the following competencies were defined as values associated with the innovational values axis that lead to the development of a corporate innovative culture:

- Self-motivation - Maintain a high level of commitment and of pride, and feel an integral part of the organization and of its results. Give your best while on duty, transmitting energy and disposition to people. Take care of the organization's things as if they were your own. Maintain motivation when facing frustration.

- Constant improvement - Seek for references on excellence, identify opportunities for improvement and put them into practice. Question the status quo, and put forward innovative solutions in the process. Take on new challenges, being ready to face them at any time.

- Self-development - Take on oneself the initiative for the refinement of one's knowledge, with respect to knowledge that is related to the work. Show a positive disposition toward the learning of new topics, to be applied on the job and to be shared with other people. Seek constant feedback related to professional upgrading and refinement.

Innovational coaches bring their skills forward to people in a way that honors the integrity underlying their work activity and commitment to making tangible transformations. We argue that innovational coaches must have the following core competences to perform effectively the MSIV tri-intersectional model of values:

- Relationship and co-creation - Build a relationship of respect and trust with the people and create an equal and synergistic partnership with them. Listen actively and provide support to the people self-expression. Keep in touch with own intuition, centered in people needs and co-create an agenda of exciting experiences, developing a fun work space.

- Questions and stretching - Help people through asking powerful questions that provoke curiosity, insight, discovery, and actions. Build together different perspectives to reframe people experience, and communication skills, mainly in detecting obvious things. Make them aware of incongruence between their thoughts, emotions, and actions. Support people to grow their self-awareness while stretching them for breakthroughs.

- Values and goals - Work with people to arouse their positive passion aligned with innovational values and help them to become aware of them. Co-create SMART (Stretching, Measurable, Achievable, Realistic and Time bounded) goals. Help the people to develop an appropriate, measurable action plan with their initiatives and target dates.

Innovational coaches may also utilize Bianchi and Steele's (2014) "Coaching for Multiple Options (CMO) Model" when assisting coachees to generate innovations. This enables them to act as an informal coach and turn everyday conversations into coaching conversations. Instead of purely asking questions, coaching for innovation is a co-creation process that motivates coachees to come up with their own innovative options and solutions.

As noted earlier, we argue that the "meta" value of MSIV is trust. The MSIV model, therefore, requires that a trusting relationship be developed between the coach and coachee, and that MSIV be viewed as a co-creation process. For this to happen, we propose to adapt the DART model of Prahalad and Ramaswang (2004):

- D stands for Dialogue, which encourages knowledge sharing and improves the understanding between coaches and people, giving them the opportunity to interject their point of view about the innovation process. 
- A stands for Access to knowledge, tools, and expertise helps people construct their own experience outcomes, broadening their views of innovations opportunities.

- $\quad \mathbf{R}$ stands for Risk sharing means that the co-creators of innovations are responsibility for dealing with both success and the risks of failure and overcoming any associated frustrations.

- $\quad \mathbf{T}$ stands for Transparency of information in the interactions, which is fundamental to enhancing participation between people participation and building trust between employees and their coaches.

In general, we suggest that innovational coaches utilize the MSIV tri-intersectional model, with its asymmetrical culture reengineering approach, in order to help coachees focus on developing and implementing sustainable innovations and to inspire people to come up with user-centric innovative options and solutions. To this end, we identify two different coaching approaches that can be applied according to the dominant values of the organization:

- The Innovational Coach - MSIV tri-intersectional model, in its asymmetrical culture reengineering, driven by emotional values.

- The Entrepreneurial Coach - MSIV tri-intersectional model, in its asymmetrical culture reengineering, driven by economic values.

Figure 6 portrays these alternative coaching approaches.

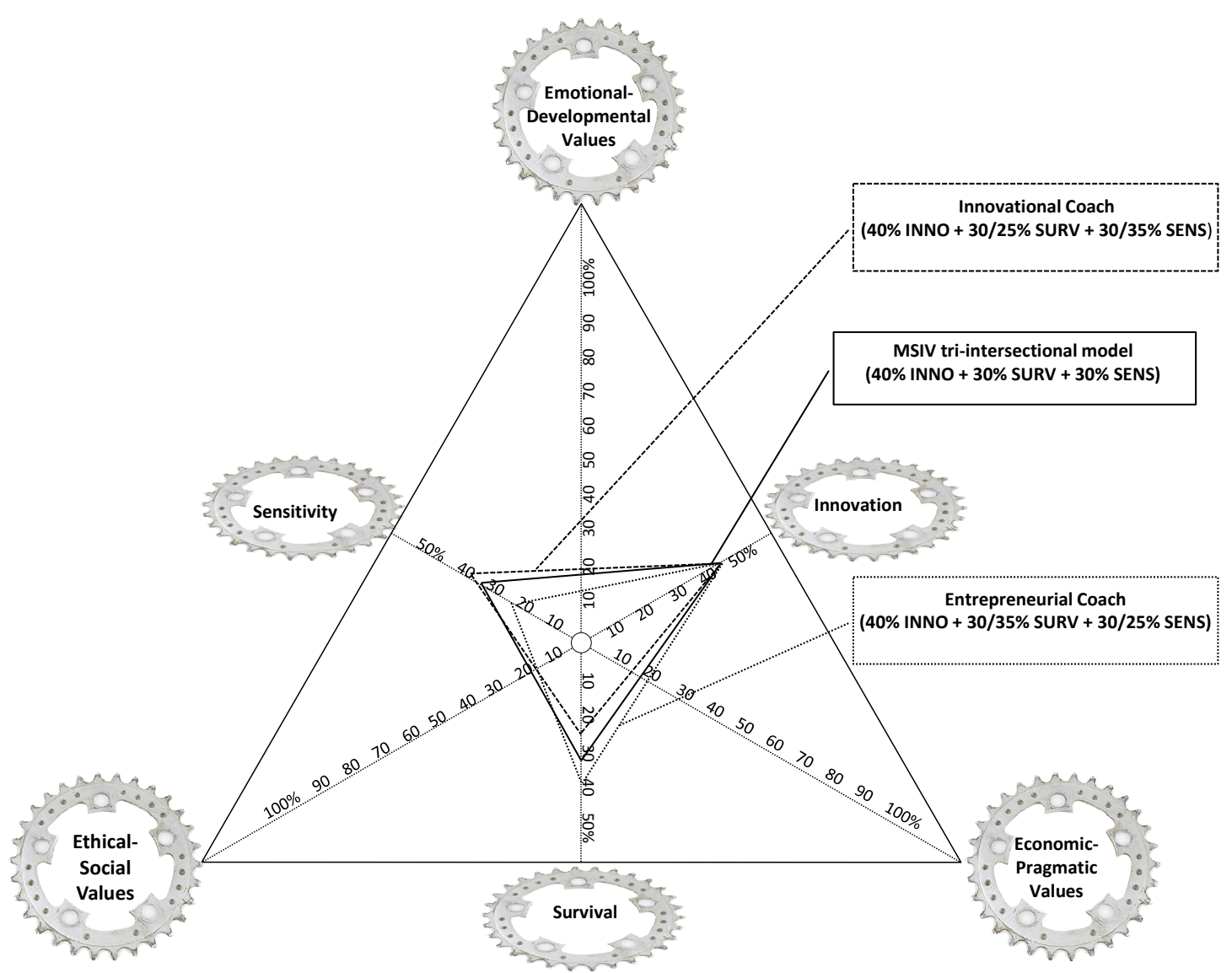

Figure 6. MSIV tri-intersection model x Innovational coach and entrepeneurial coach approaches

As noted earlier, the MSIV model (represented by the triangle formed between the three vertices of emotional-developmental, ethical-social, and economic-pragmatic values) is proposed as an asymmetrical culture reengineering model of values that serves as a management system for managers of innovative firms to integrate user-innovators, user-entrepreneurs, sustainable innovation practices and core business processes in order to achieve sustainable innovation. MSIV is typically configured in the proportion of $40 \%$ 
emotional-developmental, $40 \%$ economic-pragmatic values, and $20 \%$ ethical-social values. By averaging these proportional numbers associated with each set of vertices along an axis, an organization or individual would be able to achieve a $40 \%$ focus on innovation, a $30 \%$ focus on survival, and a $30 \%$ focus on sensitivity.

The MSIV model may also be strategically configured to serve as a tool for innovational and entrepreneurial coaches who are working to support the different goals of their coachees. Innovational coaches, for example, would skew the MSIV triangle towards emotions (the emotional-developmental values), where the coachee would identify, develop, and use a greater proportion of values connected with this vertex than ethical-social and economic-pragmatic values to achieve innovational goals. The proposed proportion of values in this configuration would be 50\% emotional-developmental, 30\% economic-pragmatic, and $20 \%$ ethical-social. By averaging these proportional numbers associated with each set of vertices along an axis, an individual or organizational would be able to achieve a $40 \%$ focus on innovation, a $25 \%$ focus on survival, and a $35 \%$ focus on sensitivity.

Entrepreneurial coaches, on the other hand, would skew the MSIV triangle towards the economic-pragmatic vertex, where the coachee would be guided to identify, develop, and use a greater proportion of economic-values than other values to achieve entrepreneurial goals. The proposed proportion of values in this configuration would be $50 \%$ economic-pragmatic, $30 \%$ emotional-developmental, and $20 \%$ ethical-social. Again, calculating the average numbers associated with each set of vertices along an axis, an individual or firm would be able to achieve a $40 \%$ focus on innovation, a $35 \%$ focus on survival, and a $25 \%$ focus on sensitivity.

\section{Conclusion}

Management by Sustainable Innovational Values (MSIV) is a strategic leadership tool that helps leaders, managers, organizations, and societies successfully deal with the context of "open sustainable innovation environments" while also face the changing and transforming world in which they need constantly innovate and renovate by offering high-quality strategies and effective solutions for addressing critical workplace problems and environment crises inherent in the 21st century. A critical success factor of MSIV is the development of an open sustainable innovation culture and management approach where leaders and managers must both "talk" sustainable innovation and "walk" its innovational paths. An open sustainable approach is effective when leaders expand the sourcing of creative ideas and innovation practices beyond the walls of their organizations while also integrating the inputs of employees, end users, and society. Firms must develop the core competencies that balance traditional management skills with innovating ones to create highly-performing organizational cultures that enable firms to "recreate the old and create the new" while meeting the constantly changing and transformative demands of the firm. Moreover, managers need to also constantly define, or define, the dominant innovation paradigm concerning shared values and how they can operate and innovate efficiently within this paradigm. Managers must provide the critical ingredients needed for delivering sustainable innovations and creating a sustainable future: values-driven organizational resources, values-driven managerial capabilities, and sustainable innovation core business processes that integrate user-driven and user-entrepreneur-based inputs and that are embedded in the organization, strategy, and culture. Finally, we would like to point out the EU-InnovatE project and the GameChanger programmeare in line with the MSIV tri-intersectional model of values philosophy, in which economic, emotional and social/ecological values are embedded in the organization culture to create long-term human, financial, and social sustainability.

\section{References}

ASTD Research. (2014). Building an Innovative Organization: The Role of Training and Development. Alexandra, VA: ASTD.

Belz, M., \& Binder, M. (2015). Sustainable Entrepreneurship: A Convergent Process Model.

Bianchi, C., \& Steele, M. (2014). Coaching for Innovation. New York: Palgrave Macmillan. http://dx.doi.org/10.1057/9781137353269

Breen, W., \& Hamel, G. (2007). The Future of Management. Boston: Harvard Business Press.

Brillo, J., \& Cosenza, C. (2013). Methodology for Hierarchization of Competences. ARIPD, 12/2013.

Brillo, J., Dolan, S., \& Kawamura, K. (2014). Coaching by Sustainable Innovational Values: The 40-30-30 tri-intersectional model of values. Effective Executive, IUP Publication, 12/2014.

Brillo, J., Dolan, S., \& Kawamura, K. (2014). Coaching by Sustainable Innovational Values (CSIV): Portraying the case of the 40-30-30 tri-intersectional model, SSRN, 12/2014.

Cavagnaro, E., \& Curiel, G. (2012). The Three Levels of Sustainability. UK: Greenleaf Publishing. 
Chesbrough, H. (2003). Open Innovation. Boston: Harvard Business Press.

Dolan, S. L. (2011). Coaching by Values, iUniverse.EUINNOVATE General Assembly: End User Integration, innovation and Entrepreneurship. Freising, 1/2015. Retrieved from www.euinnovate.com

Dolan, S. L., \& Garcia, S. (2002). Managing by values: cultural redesign for strategic organizational change at the dawn of the twenty-first century. The Journal of Management Development, 21(2), 101-117. http://dx.doi.org/10.1108/02621710210417411

Dolan, S. L., \& Raich, M. (2008). Beyond: Business and Society in Transformation. Hoboken, NJ: Palgrave Macmillan.

Dolan, S. L., Garcia, S., \& Auerbach, A. (2003). Understanding and managing chaos in organizations. International Journal of Management, 20(1), 23-36.

Dolan, S. L., Garcia, S., \& Richley, B. (2006). Managing by Values. New York: Palgrave Macmillan. http://dx.doi.org/10.1057/9780230597754

Dolan, S., Altman, Y., Capell, B., \& Raich, M. (2014). Embedded Values and Induced Spirituality in Management Education: Case of Two Successful Business Schools in Barcelona. European Business Review. Retrieved from http://www.europeanbusinessreview.com/?p=5449

Francis, D., \& Bessant, J. (2005). Targeting innovation and implications for capability development. Technovation, 25(3), 171-183. http://dx.doi.org/10.1016/j.technovation.2004.03.004

Hippel, E. (2005). Democratizing Innovation. Boston: MIT Press.

Matthew 7:12, World English Bible, American Standard Version, 1901.

Pablos-Herederoa, C., Botellab, J. L. M., \& LosSantosc, I. S. (2012). The effectiveness of open innovation practices: an application to efficient replenishment. Procedia Technology, 5, 133-140. http://dx.doi.org/10.1016/j.protcy.2012.09.015

Raich, M., Eisler, R., \& Dolan, S. L. (2014). Cyberness: The future reinvented. CreateSpace Independent Amazon Publishing.

Shell GameChanger Programme, Open innovation case, Shell Website, 3/2015. Retrieved from www.shell.com.Accessed on 3/20/2015

Sustainable Lifestyles 2.0: End User Integration and Entrepreneurship (EU-InnovatE). Retrieved from http://eu-innovate.org/en

Tidd, J., \& Bessant, J. (2013). Managing Innovation: Integrating Technological, Market and Organizational Change. Hoboken, NJ: Wiley.

Tzafrir, S. S. (2006). A universalistic perspective for explaining the relationship between HRM practices and firm performance at different points in time. Journal of Managerial Psychology, 21(2), 109-130. http://dx.doi.org/10.1108/02683940610650730

Tzafrir, S. S., \& Dolan, S. L. (2004). Trust ME: A scale for measuring employee manager trust. Journal of Management Research, 2(2), 117-134. http://dx.doi.org/10.1108/15365430480000505

Tzafrir, S. S., Harel, G., Baruch, Y., \& Dolan, S. L. (2004). The consequences of emerging HRM practices for employees trust in their managers. Personnel Review, 33(6), 628-647. http://dx.doi.org/10.1108/00483480410561529

Tzafrir, S., \& Gur, A. (2007). HRM Practices and Perceived Service Quality: The Role of Trust as a Mediator. Research and Practice in Human Resource Management, 15(2), 1-20.

Tzu, S. (1901). The Art of War. Norwalk, CT: The Puppet Press.

Wirtenberg, J. (2014). Building a Culture for Sustainability: People, Planet, and Profits in a New Green Economy. Santa Barbara, CA: ABC-CLIO.

\section{Notes}

Note 1. ASTD Research (2014). Building an Innovative Organization: The Role of Training and Development. https://www.td.org/Publications/Research-Reports/2014/Building-An-Innovative-Organization

Note 2. http://eu-innovate.org/en 


\section{Copyrights}

Copyright for this article is retained by the author(s), with first publication rights granted to the journal.

This is an open-access article distributed under the terms and conditions of the Creative Commons Attribution license (http://creativecommons.org/licenses/by/3.0/). 